\title{
The Trimalaconothrus species from South Africa (Acari: Oribatida: Malaconothridae)
}

\author{
Yoshinori Yamamoto ${ }^{1} \&$ Louise Coetzee ${ }^{2}$ \\ ${ }^{1}$ Wakayama Prefectural School for the Blind, 949-23 Fuchu, Wakayama-shi, Wakayama, 649-6338 Japan \\ E-mail: yoshi19@pop 21.odn.ne.jp \\ ${ }^{2}$ National Museum, 36 Aliwal Street, Bloemfontein 9300, South Africa \\ E-mail: acarol@nasmus.co.za
}

\begin{abstract}
Five new species of the genus Trimalaconothrus, T. binodulus, T. duoaculeus, T. obesus, T. punctus and T. rectus, from South Africa are described. A key to species of the family Malaconothridae (Malaconothrus and Trimalaconothrus) of South Africa is given.
\end{abstract}

Key words - Acari, Oribatida, Malaconothridae, Trimalaconothrus, new species, South Africa.

\section{Introduction}

Weigmann (1997) published a detailed report on morphology and phylogeny of the central European representatives of Malaconothroidea. As far as the family Malaconothridae is concerned, this study was, however, restricted to the genera Malaconothrus Berlese 1904 and Trimalaconothrus Berlese 1916, as these are the only Malaconothridae occurring in the Palearctic Region. The two genera are separated by monodactyle legs in Malaconothrus and tridactyle legs in Trimalaconothrus, which is regarded as plesiomorphous in adults.

Two more genera belong to this family, namely Fossonothrus Hammer 1962 and Zeanothrus Hammer 1966, both genera are similar to Trimalaconothrus in having tridactyle tarsi. The most important differences between Fossonothrus and Trimalaconothrus are the indentation of the median part of the notogaster (forming a cavity which separates the two longitudinal dorsal ridges), the lateral displacement of notogastral setae $c_{1}$ (thus $\left.\left(c_{1}-c_{1}\right)>\left(d_{1}-d_{1}\right)\right)$, and the convex shape of the medial part of the posterior border of epimera IV. Fossonothrus presently comprises three species viz. F. latus Hammer 1962 from the Andes mountains, F. novaezealandicus Hammer 1966 from New Zealand and F. wallworki Stary \& Block 1995 from South Georgia in the sub-Antarctic. Only one species belongs to the genus Zeanothrus, namely Z. elegans Hammer 1966, described from New Zealand. Hammer (1966) distinguished this genus from Trimalaconothrus by the arched projection ("anterior border projects as a broad tongue" Hammer 1966 p. 21) of the anterior border of the notogaster and the degree of separation between the left and right epimera (coxisterni).

This is the second report of the family Malaconothridae from South Africa, and first record of the genus

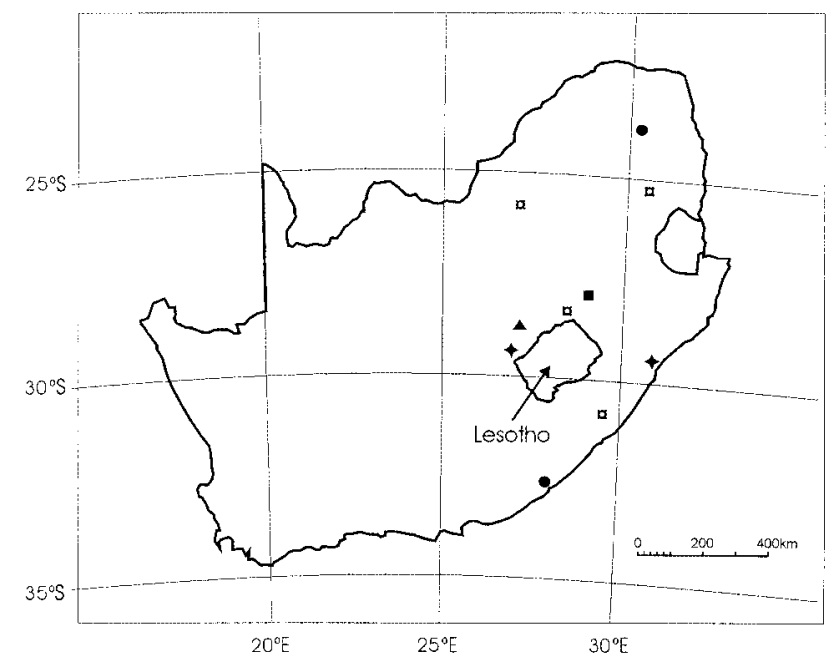

Fig. 1. Map of localities of Trimalaconothrus in South Africa. Triangle: Trimalaconothrus binodulus sp. nov. Circles: $T$. duoaculeus sp. nov. Solid square: T. obesus sp. nov. Open squares: T. punctus sp. nov. Diamonds: T. rectus sp. nov.

Trimalaconothrus from South Africa. Representatives of this genus are not widely distributed and occur mainly but not exclusively, in moist to wet habitats, as well as being completely aquatic.

Trimalaconothrus binodulus sp. nov. (Figs. 2-8)

Measurements $(\mu \mathrm{m})$. Body length 572-600 (av. 584), width 326-340 (av. 333).

Color. Yellowish brown.

Prodorsum. Rostrum rounded. Pedotectum I well 
Table 1. Localities of Trimalaconothrus in South Africa.

\begin{tabular}{|c|c|c|c|c|c|}
\hline No. ${ }^{1}$ & Distribution $^{2}$ & Locus $^{3}$ & Collecting date & Collector & Habitat \\
\hline \multicolumn{6}{|c|}{ Trimalaconothrus binodulus sp. nov. } \\
\hline 3795 & Korannabberg, FS & $2827 \mathrm{Cc}$ & 11 Sep 1993 & C. de Vries & \multirow{4}{*}{$\begin{array}{l}\text { Sediment in natural rock pools on mountain. } \\
\text { Sediment in natural aquaria }(\# 4) \text { on mountain. } \\
\text { Sediment in natural aquaria }(\# 5) \text { on mountain. } \\
\text { Sediment in natural aquaria }(\# 35) \text { on mountain. }\end{array}$} \\
\hline 3797 & Korannabberg, FS & $2827 \mathrm{Cc}$ & 11 Sep 1993 & C. de Vries & \\
\hline 3798 & Korannabberg, FS & $2827 \mathrm{Cc}$ & 11 Sep 1993 & C. de Vries & \\
\hline 3799 & Korannabberg, FS & $2827 \mathrm{Cc}$ & 11 Sep 1993 & C. de Vries & \\
\hline \multicolumn{6}{|c|}{ Trimalaconothrus duoaculeus sp. nov. } \\
\hline 3661 & Letsitele, LP & $2330 \mathrm{Cd}$ & 24 Oct 1989 & C.J. Cilliers & \multirow{2}{*}{$\begin{array}{l}\text { In dam on Salvinia molesta. } \\
\text { Decomposed plant debris. }\end{array}$} \\
\hline 3662 & Cintsa, EC & $3228 \mathrm{Ca}$ & 1 Dec 1989 & C.M. Engelbrecht & \\
\hline \multicolumn{6}{|c|}{ Trimalaconothrus obesus sp. nov. } \\
\hline 1889 & Verkykerskop, FS & $2729 \mathrm{Cd}$ & 20 Jan 1982 & J.P. Eksteen & \multirow{2}{*}{$\begin{array}{l}\text { In moss at natural fountain. } \\
\text { In moss at natural fountain. }\end{array}$} \\
\hline 1890 & Verkykerskop, FS & $2729 \mathrm{Cd}$ & 20 Jan 1982 & J.P. Eksteen & \\
\hline \multicolumn{6}{|c|}{ Trimalaconothrus punctus sp. nov. } \\
\hline 869 & Rustenburg, NW & $2527 \mathrm{Cb}$ & 21 Apr 1962 & A.J. Els & \multirow{5}{*}{$\begin{array}{l}\text { Soil under indigenous shrub. } \\
\text { Moist soil under indigenous b } \\
\text { Moist soil in dense indigenou } \\
\text { Moist soil with plant debris. } \\
\text { Moist soil with plant debris. }\end{array}$} \\
\hline 1985 & Kokstad, KZN & $3029 \mathrm{Db}$ & 2 Oct 1982 & C.M. Engelbrecht & \\
\hline 2892 & Sabie, MP & $2530 \mathrm{Bb}$ & 31 Jul 1982 & R. Earl & \\
\hline 2900 & Golden Gate, FS & $2828 \mathrm{Bc}$ & 12 Nov 1982 & C.M. Engelbrecht & \\
\hline 3463 & Golden Gate, FS & $2828 \mathrm{Da}$ & 18 Mrt 1986 & C.M. Engelbrecht & \\
\hline \multicolumn{6}{|c|}{ Trimalaconothrus rectus sp. nov. } \\
\hline 1634 & Ladybrand, FS & $2927 \mathrm{Ab}$ & 30 Sep 1981 & C.M. Engelbrecht & \multirow{4}{*}{$\begin{array}{l}\text { Moist moss near stream under shady trees. } \\
\text { Organic-rich soil with indigenous plants. } \\
\text { Organic-rich soil with dry Pine debris. } \\
\text { Moist organic-rich soil in indigenous forest. }\end{array}$} \\
\hline 1636 & Ladybrand, FS & $2927 \mathrm{Ab}$ & 30 Sep 1981 & C.M. Engelbrecht & \\
\hline 1638 & Ladybrand, FS & $2927 \mathrm{Ab}$ & 30 Sep 1981 & C.M. Engelbrecht & \\
\hline 1933 & Ballitoville, KZN & $2931 \mathrm{Ca}$ & 2 Sep 1982 & C.M. Engelbrecht & \\
\hline
\end{tabular}

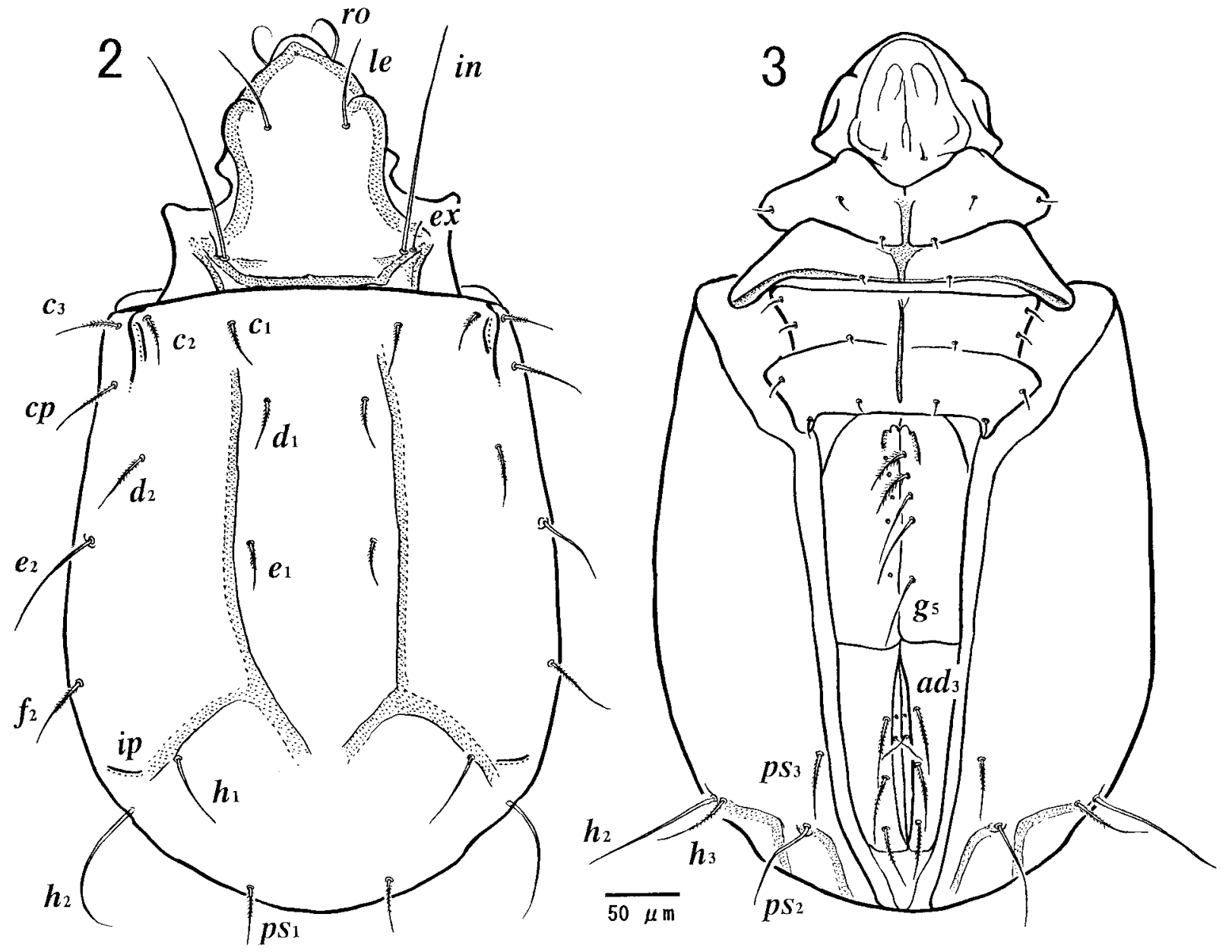

Figs. 2-3. Trimalaconothrus binodulus sp. nov. (holotype)-2. Dorsal view; 3. Ventral view. 


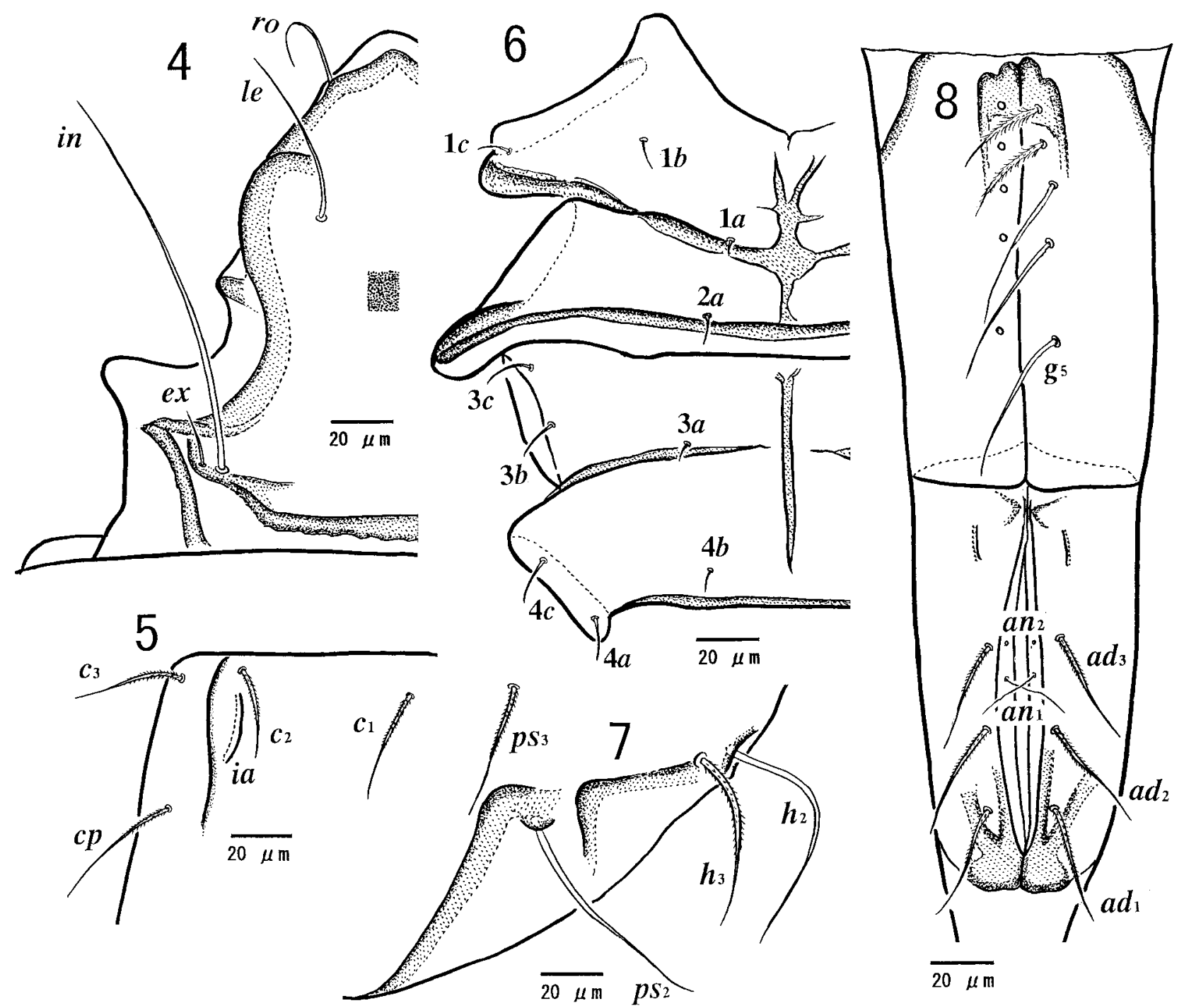

Figs. 4-8. Trimalaconothrus binodulus sp. nov. (holotype)- 4. Prodorsum; 5. Antero-lateral view of notogaster; 6. Epimerata I-IV; 7. Postero-lateral part of notogaster (ventral view); 8. Genital and anal plates

marked, pointed. Lamellar ridge S-shaped and very conspicuous; anteriorly broadened and curved, projecting over lateral margin of prodorsum; the posterior part thickened behind interlamellar (in) and exobothridial setae (ex). Transverse ridge present between interlamellar setae. All prodorsal setae smooth and thin; rostral seta (ro) curled; lamellar seta (le) of medium length; interlamellar setae very long reaching anterior rostral margin; exobothridial seta very short; relative length and mutual distances between setae as follows: in $>l e>r o>e x ; r o \fallingdotseq(r o-r o) ; l e>(l e-l e)$; in $>($ in-in $) ; e x<(e x-e x)$. Integument of prodorsum minutely punctate.

Notogaster. Anterior margin of notogaster slightly convex. Lateral side of notogaster gently swollen. Notogastral setae $c_{1}, c_{2}, c_{3}, c p, d_{1}, d_{2}, e_{1}, f_{2}, h_{3}, p s_{1}$ and $p s_{3}$ very weakly barbed, short; the remaining setae $e_{2}, h_{1}, h_{2}$ and $p s_{2}$ smooth, thin, and longer than barbed setae. Relative lengths and mutual distances of notogastral setae as follows: $h_{2}>e_{2}>p s_{2}>$ $h_{1}>h_{3}>f_{2}>c p=p s_{3}>d_{2}=c_{3}=p s_{1}>c_{1}=c_{2}=d_{1}=e_{1} ;\left(h_{1}-h_{1}\right)>\left(c_{1}-\right.$ $\left.c_{1}\right)>\left(e_{1}-e_{1}\right)>\left(d_{1}-d_{1}\right) ;\left(h_{1}-h_{1}\right)=1.8 \times\left(c_{1}-c_{1}\right) ;\left(c_{1}-c_{2}\right)=2.7 \times\left(c_{2}-\right.$ $\left.c_{3}\right)$. Parallel ridges running laterally of setae $d_{1}$ and $e_{1}$, bifurcating posteriorly, ending posterolaterally a little beyond seta $h_{1}$ and posteromedially, not touching each other; short longitudinal ridge present laterally of seta $c_{2}$ and lyriffisure $i a$. Integument of notogaster finely punctate.

Ventral side. Anogenital chaetotaxy 5-0-2-3. Anal plate with two setae; $a n_{2}$ minute, hardly visible, situated at the same level of $a d_{3} ; a n_{1}$ very conspicuous and long, situated at mid-level between $a d_{2}$ and $a d_{3}$. Adanal plate with three barbed setae. Genital plate with 5 long setae; anterior two setae finely barbed and shorter than other genital setae, posterior three setae smooth and long. Relative lengths and mutual distances of genital setae as follows: $g_{5}=g_{4}>g_{3}=g_{2}>$ $g_{1} ;\left(g_{5}-g_{4}\right)>\left(g_{4}-g_{3}\right) \geqq\left(g_{3}-g_{2}\right)=\left(g_{2}-g_{1}\right) ;\left(g_{5}-g_{4}\right)=2.3 \times\left(g_{2}-g_{1}\right)$. Epimera IV fused in the posterior $1 / 5$. Setal formula of epimera: 3-1-3-3. All epimeral setae smooth and short, 


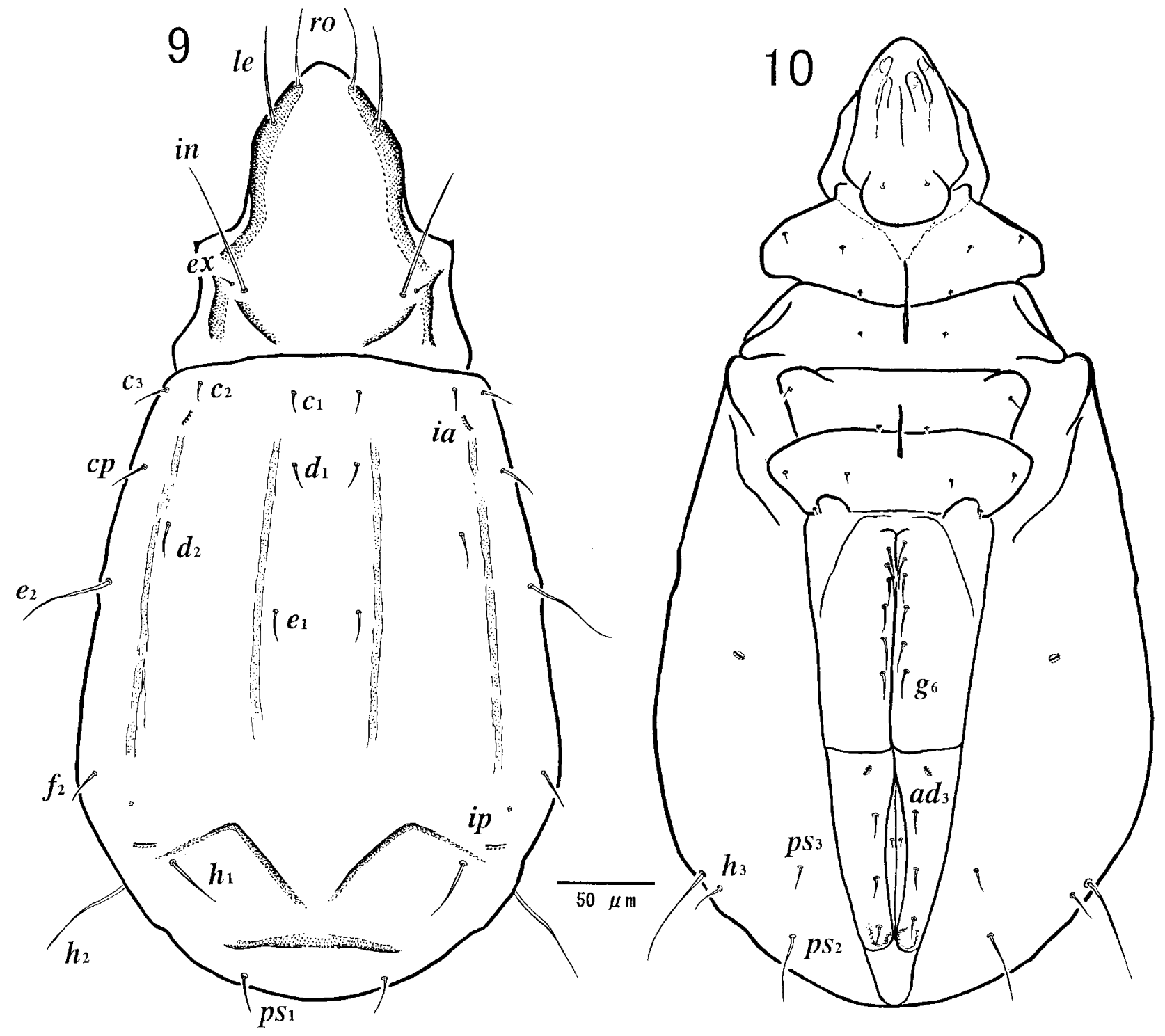

Figs. 9-10. Trimalaconothrus duoaculeus sp. nov. (holotype) - 9. Dorsal view; 10. Ventral view.

although variable in length; $3 b, 3 c, 4 a$ and $4 c$ longest, $1 b$, $1 c, 2 a$ and $4 b$ moderately long and the remainder $1 a$ and $3 a$ minute. Two pairs of hook-like ridges present posteroventrally on notogaster; lateral ridge extended from $h_{3}$, running medially towards $p s_{2}$ but sharply bent posteriorly at point lateral to $p s_{2}$, medial ridge extended from $p s_{2}$, running medially towards posterior end of anal plate and then bent posteriorly. Integument of epimera minutely punctate.

Material examined. Holotype and 21 paratypes from St. 3795-1. Rock pools with vegetation on mountain. Korannaberg, Free State. $28^{\circ} 53^{\prime}$ S, $27^{\circ} 15^{\prime}$ E. 11-IX-1993. C. de Vries. The holotype (NMB 3795.1.1) and 10 paratypes (NMB 3795.1.2) will be deposited in the Acarology collection of the National Museum Bloemfontein, South Africa, and 11 paratypes (NSMT-Ac 11740-11750) in the collection of the National Science Museum, Tokyo.

Remarks. Five Trimalaconothrus species, T. aquatilis
Fain, Lambrechts \& Wauthy 1990 from Bergium, T. brevisetiger Yamamoto \& Aoki 1998 from China $T$. heterotrichus Wallwork 1973 from Cameroon, $T$. magnilamellatus Yamamoto 1997 from Japan and $T$. nipponicus Yamamoto \& Aoki 1971 from Japan have partly barbed notogastral setae, i.e. some setae barbed and some smooth. The present species is similar to $T$. aquatilis in having a marked pedotectum I, but it differs from the latter in several respects namely (1) rostral and lamellar setae smooth, (2) interlamellar seta very long, (3) S-shaped lamellar ridge present, (4) some dorsal ridges present, (5) notogaster almost U-shaped, (6) 5 pairs of genital setae, two anterior pairs barbed, three posterior pairs smooth, and (7) all adanal setae barbed.

Etymology. The specific name "binodulus" refers to the short antero-lateral ridges of the notogaster. 

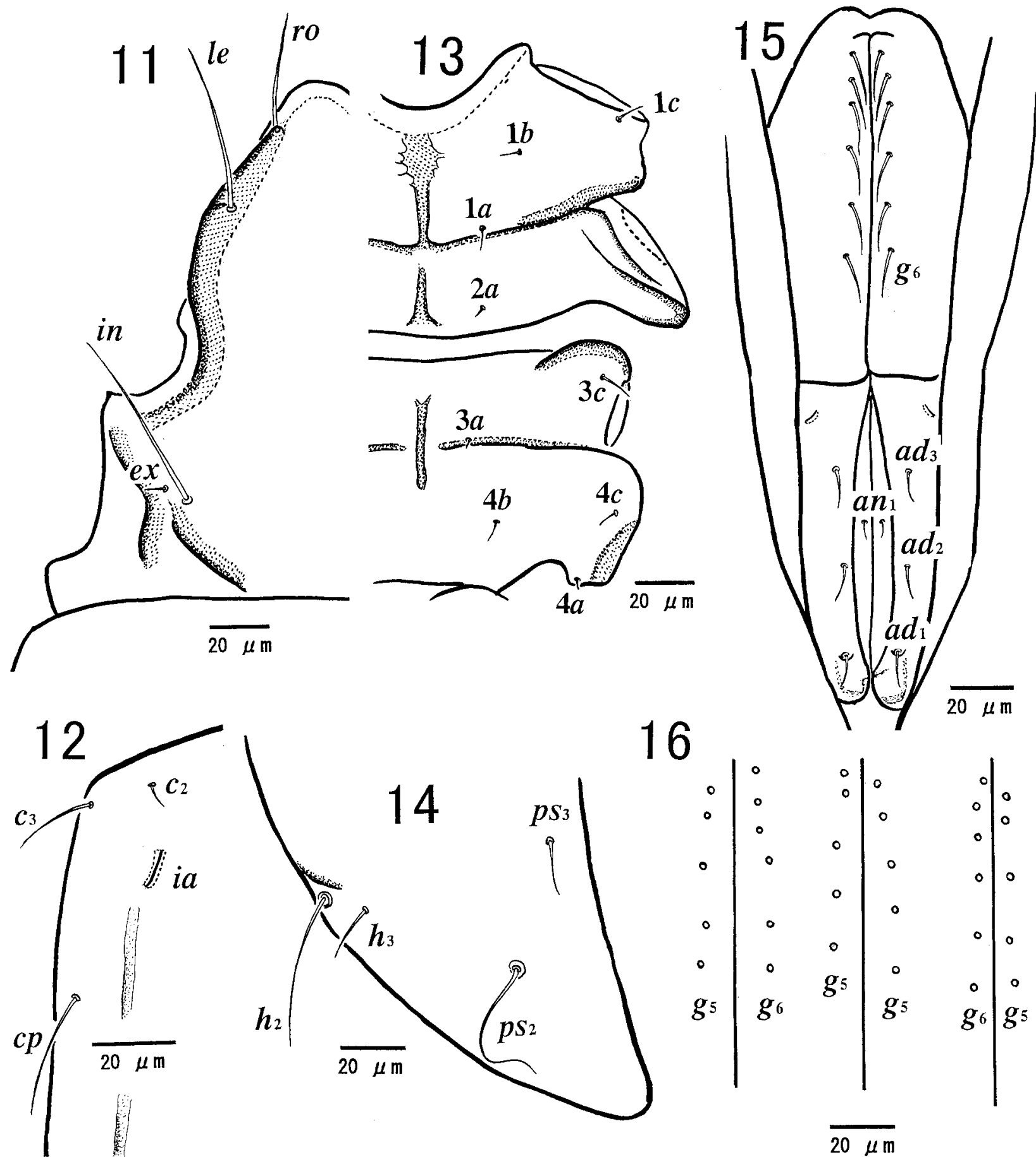

16

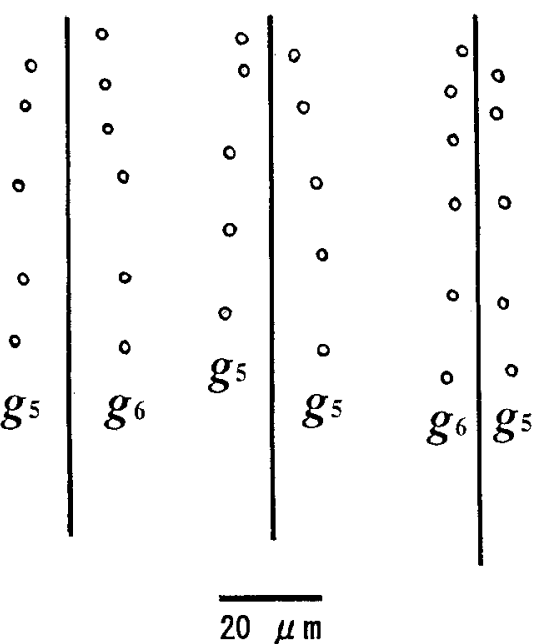

Figs. 11-16. Trimalaconothrus duoaculeus sp. nov. (holotype) - 11. Prodorsum; 12. Antero-lateral part of notogaster; 13. Epimerata IIV; 14. Postero-lateral part of notogaster (ventral view); 15. Genital and anal plates; 16. Variations in the arrangement of genital setae (the longitudinal lines indicate the median slit of genital aperture).

Trimalaconothrus duoaculeus sp. nov.

(Figs. 9-16)

Measurements $(\mu \mathrm{m})$. Body length 488-506 (av. 496), width 254-262 (av. 258).

Color. Yellowish brown.
Prodorsum. Rostrum narrow and rounded. Pedotectum I conspicuous, strongly projecting and sharply pointed. Lamellar ridge inconspicuous, long, anteriorly reaching base of rostral seta; the posterior part thickened behind interlamellar and exobothridial setae; two distinct ridges present posterior to in and ex, the lateral one located longitudinally, the medial one oblique. All prodorsal setae 


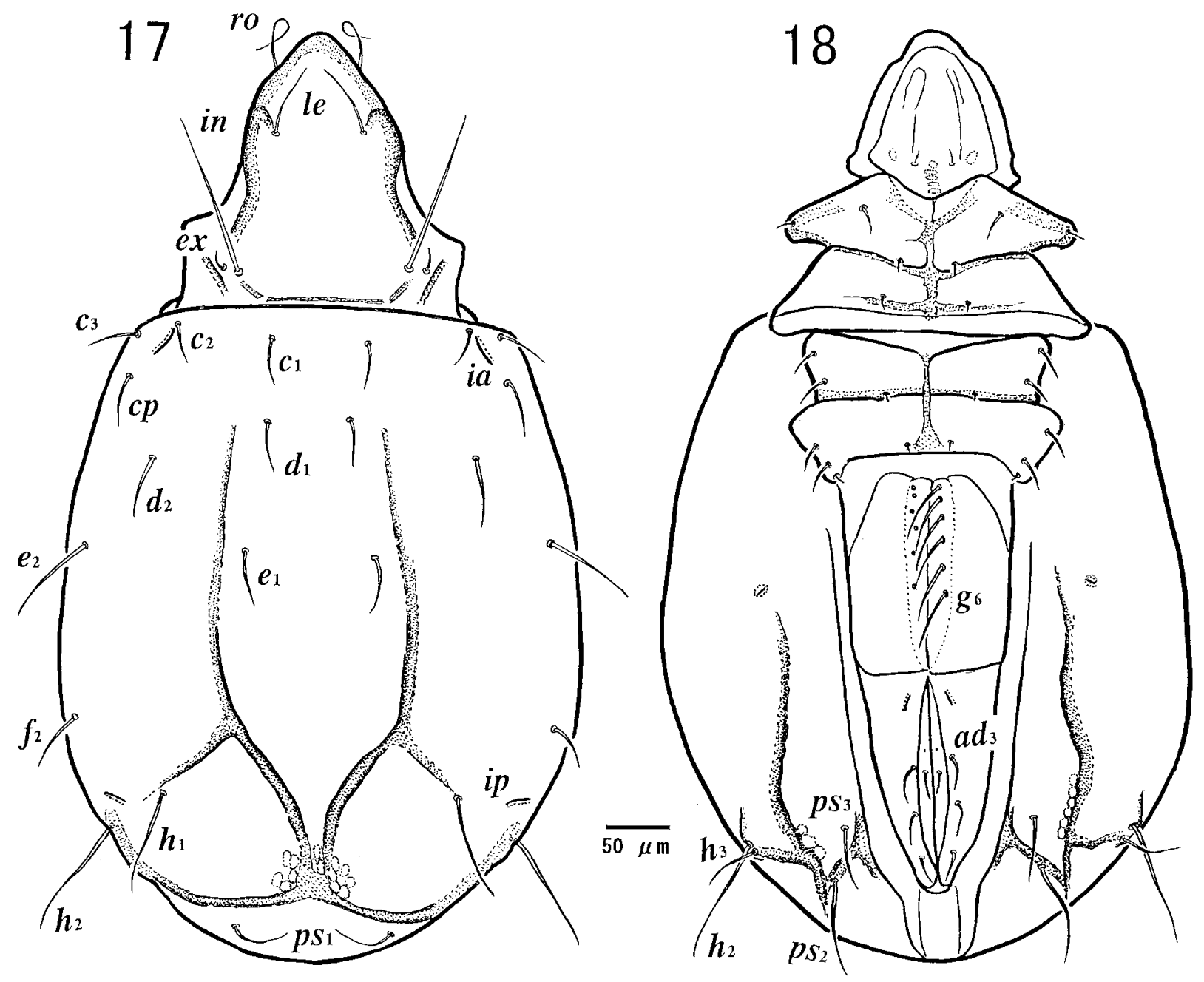

Figs. 17-18. Trimalaconothrus obesus sp. nov. (holotype) - 17. Dorsal view; 18. Ventral view.

smooth and thin; lamellar seta situated near prodorsal margin; exobothridial seta very short; relative lengths and mutual distances between setae as follows: in $>l e>r o>e x$; ro $>($ ro-ro $)$; le $=(l e-l e) ;$ in $<($ in-in $)$; ex $<(e x-e x)$. Integument of prodorsum minutely punctate.

Notogaster. Postero-lateral side gently swollen. All notogastral setae smooth and thin. Relative lengths and mutual distances of setae as follows: $h_{2}>e_{2}>p s_{2}>h_{1}>c_{3}=c p=$ $d_{2}=\mathrm{f}_{2}=p s_{1}>c_{1}=c_{2}=d_{1}=e_{1}=p s_{3}=h_{3} ;\left(h_{1}-h_{1}\right)>\left(e_{1}-e_{1}\right)>\left(c_{1}-c_{1}\right)=\left(d_{1}-\right.$ $\left.d_{1}\right) ;\left(h_{1}-h_{1}\right)=4.4 \times\left(c_{1}-c_{1}\right)$. Two pairs of faint, parallel longitudinal ridges present on notogaster; inverted W-shaped ridge present on posterior part of notogaster; straight transverse ridge situated posteriorly on notogaster just in front of setae $p s_{1}$, where notogaster shows a deep concavity. Integument of notogaster finely punctate.

Ventral side. Anogenital chaetotaxy 5/6-0-1-3. Anal plate provided with one minute seta, situated at a level a little posterior to $a d_{3}$. Adanal plate with three short setae. Mutual distances of adanal setaeas $\left(a d_{3}-a d_{2}\right)>\left(a d_{2}-a d_{1}\right)$. Genital plate with 5-6 short setae as long as adanal setae. Epimera II, III and IV partly fused: epimera II fused in the anterior $1 / 4$; epimera III in the anterior $1 / 3$ and epimera IV in the posterior $2 / 3$. Setal formula of epimera: $3-1-2-3$. All epimeral setae short, smooth, thin and variable in length; $3 c$ moderately long, $1 a, 1 b, 1 c, 4 b, 4 c$ short and the remaining setae $2 a, 3 a$ and $4 a$ minute, $3 b$ absent. Integument of epimera minutely punctate.

Material examined. Holotype and 11 paratypes from St. 3661. On Salvinia molesta. Letsitele, Limpopo Province. $23^{\circ} 53^{\prime} \mathrm{S}, 30^{\circ} 23^{\prime}$ E. $24-\mathrm{X}-1989$. C. J. Cilliers. The holotype (NMB 3661.3.1) and 5 paratypes (NMB 3661.3.2) will be deposited in the Acarology collection of the National Museum Bloemfontein, South Africa, and 6 paratypes (NSMT-Ac 11751-11756) in the collection of the National Science Museum, Tokyo.

Remarks. The present species is very similar to Trimalaconothrus scimitarum Tarras-Wahlberg 1985 from Kenya, in having sharply pointed pedotectum I, oblique ridge posterior to interlamellar seta and short notogastral setae ( $c$ and $d$ series), but it is distinguished from $T$. scimitarum by (1) small body size, (2) longer lamellar ridge, (3) short notogastral setae $h_{1}$ and $p s_{2}$, (setae $h_{1}$ and $p s_{1}$ 


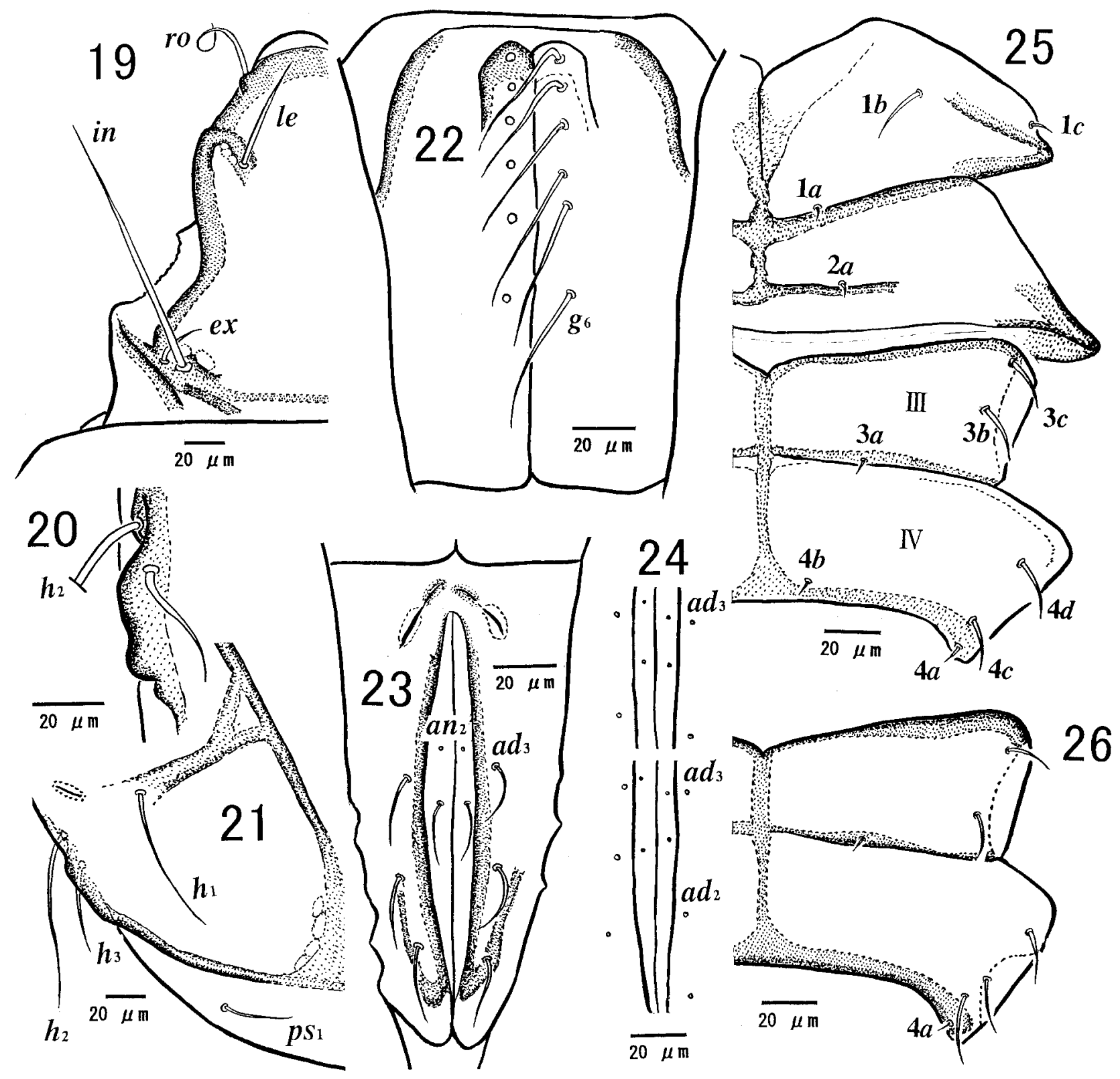

Figs. 19-26. Trimalaconothrus obesus sp. nov. (holotype) - 19.Prodorsum; 20. Seta $h_{3}$ (ventral view); 21. Postero-lateral part of notogaster (dorsal view); 22. Genital plate; 23. Anal plate; 24. Variation of anal and adanal setae; 25. Epimerata I-IV; 26. Variation of epimerata IV.

approximately $2 \times d_{1}$ in $T$. duoaculeus sp. nov.; setae $h_{1}$ and $p s_{2}$ approximately $5 \times d_{1}$ in $T$. scimitarum), (4) notogastral seta $d_{2}$ inserted more laterally, (5) two pairs of parallel ridges present longitudinally on notogaster, (6) inverted $\mathrm{W}$ shaped ridge in posterior part of notogaster, (7) straight transverse ridge present anterior to setae $p s_{1}$, and (8) integument of notogaster finely punctate.

Etymology. The specific name "duoaculeus" refers to the sharply pointed pedotectum I.
Trimalaconothrus obesus sp. nov.

(Figs. 17-26)

Measurements $(\mu \mathrm{m})$. Body length 656-708 (av. 687), width 384-416 (av.395).

Color. Yellowish brown.

Prodorsum. Rostrum narrow and rounded anteriorly. Pedotectum I obtuse. Lamellar ridge conspicuously Sshaped; the anterior end sharply curved medially; the posterior part thickened behind interlamellar and exobothridial setae, forming an acute angle laterally of exobothridial seta; 


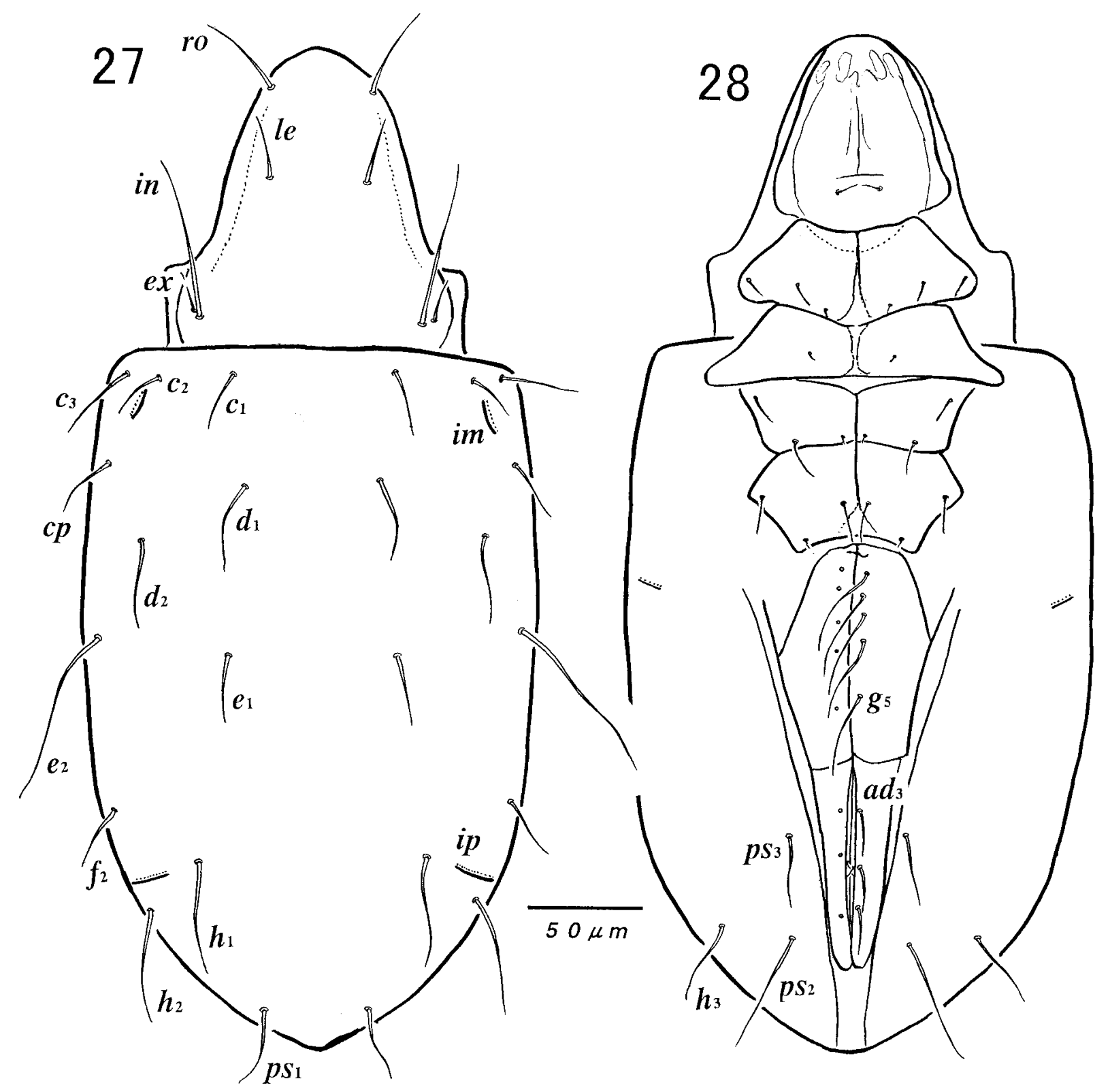

Figs. 27-28. Trimalaconothrus punctus sp. nov. (holotype) - 20. Dorsal view; 21. Ventral view.

interlamellar ridge present on posterior part of prodorsum. All prodorsal setae smooth and thin; rostral seta curled; lamellar seta short; interlamellar seta long but not reaching the anterior end of the prodorsum; exobothridial seta very short; relative length and mutual distances between setae as follows: in $>r o>l e>e x ;$ ro $>(r o-r o) ; l e<(l e-l e)$; in $=($ inin); ex $<(e x-e x)$. Integument of prodorsum densely covered with minute granules.

Notogaster. Lateral side of notogaster gently swollen. All notogastral setae smooth and thin. Relative lengths and mutual distances of notogastral setae as follows: $h_{3} \geqq h_{2}>$ $h_{1} \geqq e_{2}>c p=d_{2}=e_{1}=f_{2}>c_{1}=c_{2}=c_{3}=d_{1} ;\left(h_{1}-h_{1}\right)>\left(c_{1}-c_{1}\right)=\left(e_{1}-\right.$ $\left.e_{1}\right)>\left(d_{1}-d_{1}\right) ;\left(h_{1}-h_{1}\right)=3.2 \times\left(c_{1}-c_{1}\right)$. Parallel ridges running laterally of setae $d_{1}$ and $e_{1}$, bifurcating posteriorly, partly extending posterolaterally towards seta $h_{1}$, partly extending posteromedially and uniting to form a V-shaped ridge; transverse ridge present near the posterior end of notogaster just in front of setae $p s_{1}$, where notogaster shows a deep concavity. Some light spots sometimes present at posterior part of V-shaped ridge. Integument of notogaster densely covered with minute granules.

Ventral side. Anogenital chaetotaxy 6-0-2-3. Anal plate with two setae; $a n_{2}$ minute, hardly visible, situated at a level a little posterior or anterior to $a d_{3}$; $a n_{1}$ very conspicuous, as long as $a d_{3}$, situated at the same level or a little posterior to $a d_{3}$. Adanal plate with three setae. Genital plate with 6 long setae; one paratype specimen with 7 setae. In all epimera left and right side fully separated. Some paratypes 


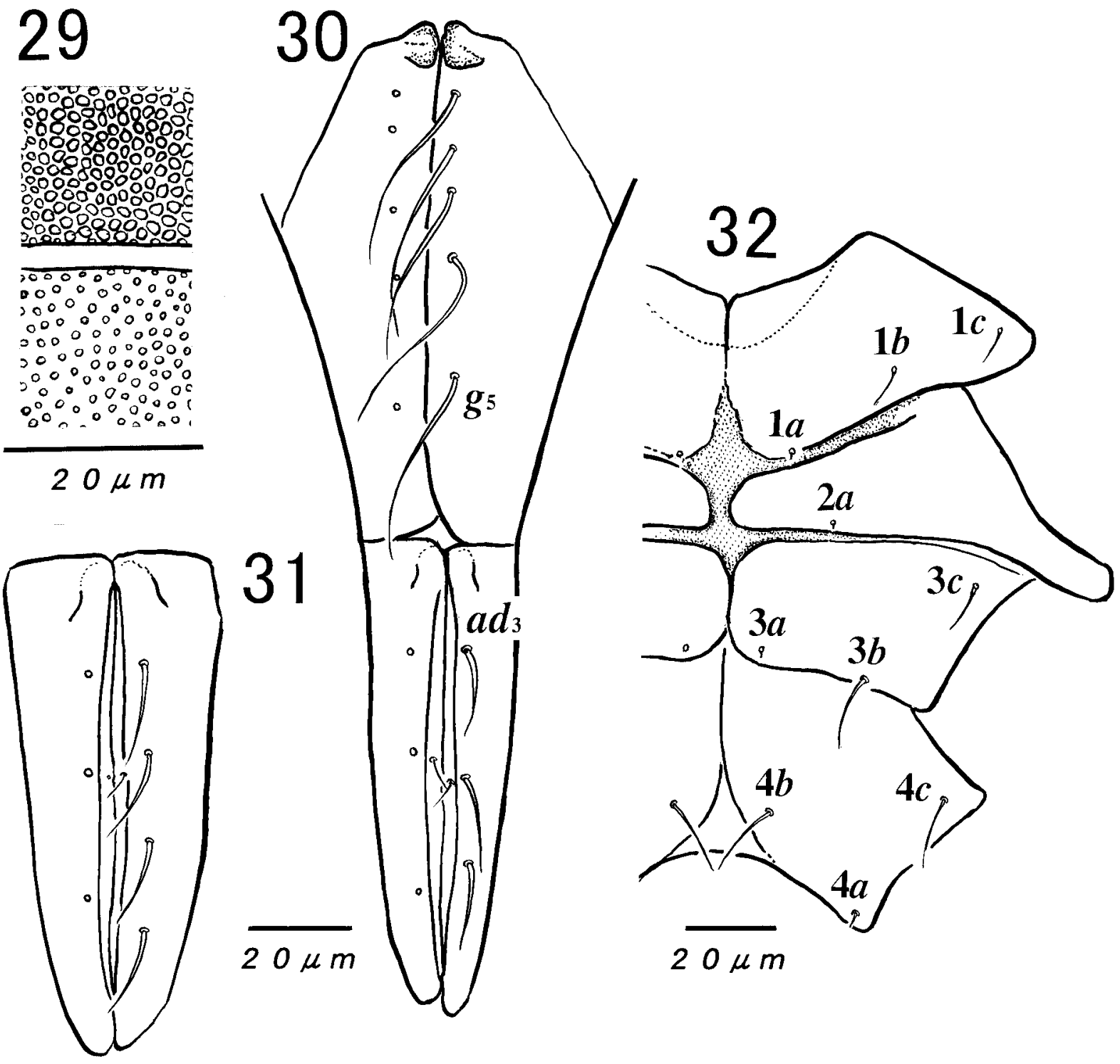

Figs. 29-32. Trimalaconothrus punctus sp. nov. (holotype) - 29. Integument of prodorsum (above) and notogaster (below); 30. Genital and anal plates; 31. Variation of adanal setae; 32. Epimerata I-IV.

having 4 setae on epimera IV. Setal formula of epimera: 31-3-3/4. All epimeral setae smooth, thin and variable in length; $1 b, 3 b, 4 c$ and $4 d$ (when present) longest, $1 c$ and $3 c$ moderately long and the remainder ( $1 a, 2 a, 3 a, 4 a$ and $4 b)$ minute. Integument of epimera covered by small, dense granules.

Material examined. Holotype and 13 paratypes from St. 1889-1. Moss under overhanging cliff on southern rock face. Verkykerskop, Free State. $28^{\circ} 53^{\prime} \mathrm{S}, 29^{\circ} 16^{\prime}$ E. 20-I1982. J. Eksteen. The holotype (NMB 1889.1.1) and 6 paratypes (NMB 1889.1.2) will be deposited in the Acarology collection of the National Museum Bloemfontein, South Africa, and 7 paratypes (NSMT-Ac 11757-11763) in the collection of the National Science Museum, Tokyo.

Remarks. The present species is similar to
Trimalaconothrus australis Hammer 1958 from Argentina and Bolivia, but is distinguished from the latter by (1) small body size, (2) narrow rostrum, (3) short lamellar seta, and (4) 6 pairs of genital setae.

Etymology. The specific name "obesus" refers to the shape of notogaster.

Trimalaconothrus punctus sp. nov.

(Figs. 27-32)

Measurements $(\mu \mathrm{m})$. Body length 424-448 (av. 436), width 208-232 (av. 219).

Color. Yellowish brown.

Prodorsum. Rostrum broadly rounded. Pedotectum I obtuse. Lamellar ridge inconspicuous. All prodorsal setae thin and smooth. Relative lengths and mutual distances of 


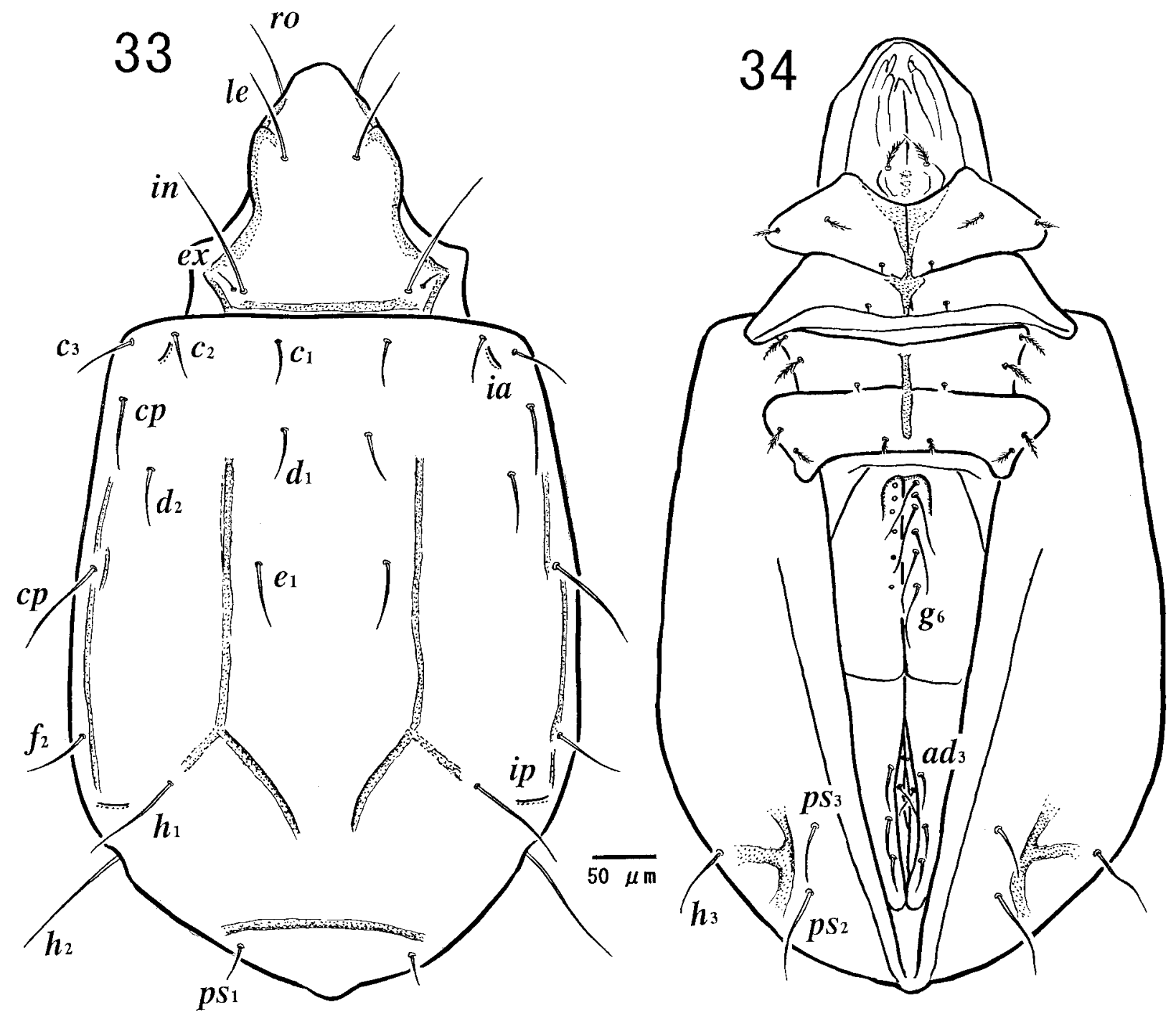

Figs. 33-34. Trimalaconothrus rectus sp. nov. (holotype) - 26. Dorsal view; 27. Ventral view.

prodorsal setae as follows: in $>r o>l e>e x ; 2.5 \times l e \fallingdotseq i n ; r o$ $\fallingdotseq($ ro-ro $)$; le $<$ (le-le); in $<$ (in-in); ex $<$ (ex-ex). Integument of prodorsum with dense punctation.

Notogaster. Shield-shaped; anterior margin of notogaster almost straight; lateral margins parallel in anterior half, converging in posterior half; posterior end not smoothly rounded, but pointed. Notogastral ridges absent. All notogastral setae thin and smooth. Relative mutual distances of notogastral setae as follows: $\left(h_{1}-h_{1}\right)>\left(c_{1}-c_{1}\right) \fallingdotseq\left(e_{1}\right.$ $\left.e_{1}\right)>\left(d_{1}-d_{1}\right) ; 2.1 \times\left(c_{2}-c_{3}\right) \fallingdotseq\left(c_{1}-c_{2}\right)$. Relative lengths of notogastral setae as follows: $e_{2}>p s_{2}>h_{1} \fallingdotseq h_{2}>c_{3} \fallingdotseq d_{1} \fallingdotseq d_{2}$ $\fallingdotseq h_{3}>e_{1} \fallingdotseq p s_{1} \fallingdotseq p s_{3}>c_{1} \fallingdotseq c p \fallingdotseq f_{2}>c_{2}$. Lyrifissure ip long and situated close to notogastral margin. Integument of notogaster with dense punctation but sparser than those on prodorsum.

Ventral side. Anogenital chaetotaxy 5-0-1-3. Genital plate with 5 thin, smooth and long setae; setal distances generally as follows: $\left(g_{1}-g_{2}\right)=\left(g_{2}-g_{3}\right)<\left(g_{3}-g_{4}\right)<\left(g_{4}-g_{5}\right)$. Anal plate with one short seta, situated at the level of $a d_{2}$. Adanal plate with 3 setae. Setal formula of epimerata: 3-1-3-3; all epimeral setae smooth, thin and variable in length; $3 b, 4 b$ and $4 c$ longest, $1 b, 1 c$ and $3 c$ moderately long and the remaining setae $1 a, 2 a, 3 a$ and $4 a$ minute; $1 b$ situated further posterior than usual.

Material examined. Holotype from St. 2892. Moist soil in dense indigenous forest. Sabie, Mpumalanga. $25^{\circ} 07^{\prime} \mathrm{S}$, $30^{\circ} 48^{\prime}$ E. 31-VII-1982. R. Earlé. One paratype from St. 2900, moist soil with plant debris. Golden Gate National Park, Free State. 12. XI. 1982. C. M. Engelbrecht. The holotype (NMB 3892.1.1) will be deposited in the Acarology collection of the National Museum Bloemfontein, South Africa, and one paratype (NSMT-Ac 11764) in the collection of the National Science Museum, Tokyo.

Remarks. This species corresponds with Trimalaconothrus joonsooi Choi 1986 from Korea in the shape of the 

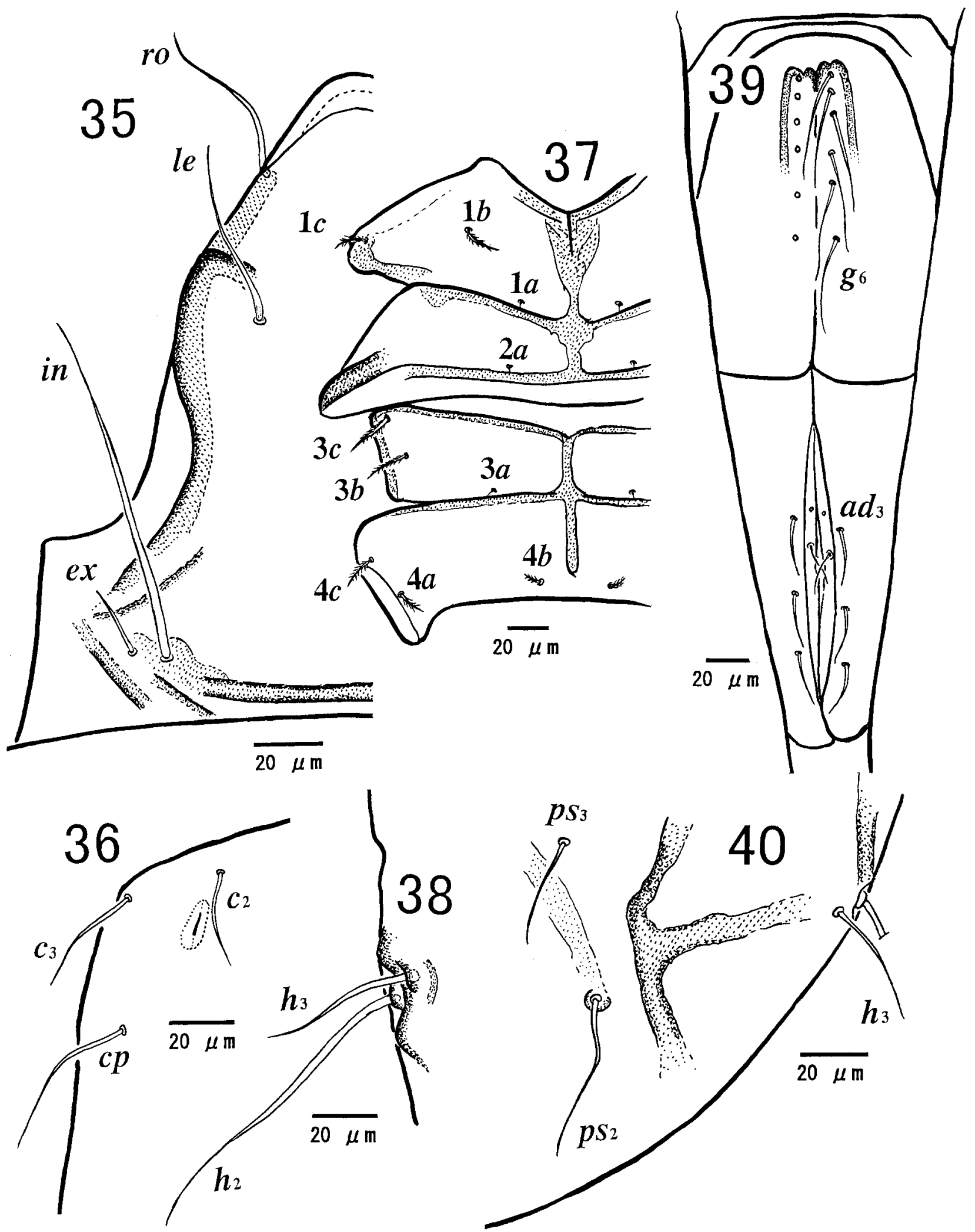

Figs. 35-40. Trimalaconothrus rectus sp. nov. (holotype) -35. Prodorsum; 36. Antero-lateral view of notogaster; 37. Epimerata I-IV; 38. Setae $h_{2}$ and $h_{3}$ (ventral view); 39. Genital and anal plates; 40. Postero-lateral part of notogaster (ventral view). 
body and the integument of the prodorsum and notogaster. However, it differs from $T$. joonsooi by the distinct difference in size between the lamellar seta and rostral seta; notogastral seta (except $e_{2}$ ) and adanal setae much shorter in $T$. punctus sp. nov. than $T$. joonsooi; notogaster without chitinized rim along the posterolateral border and with pointed posterior end in T. punctus sp. nov..

Etymology. The specific name "punctus" is derived from the structure of the integument of the prodorsum and notogaster.

\section{Trimalaconothrus rectus sp. nov.} (Figs. 33-40)

Measurements $(\mu \mathrm{m})$. Body length 672-700 (av. 687), width 368-384 (av. 376).

Color. Yellowish brown.

Prodorsum. Rostrum narrow and rounded. Pedotectum I obtuse. Lamellar ridge S-shaped; the posterior part thickened behind interlamellar and exobothridial setae; forming an acute angle laterally of exobothridial seta; interlamellar ridge present posteriorly on prodorsum. All prodorsal setae smooth and thin; exobothridial seta very short; relative length and mutual distances between setae as follows: in $>l e>r o>e x ; \quad r o \geqq(r o-r o) ; \quad l e>(l e-l e) ;$ in $<($ in-in $) ;$ ex $<(e x-e x)$. Integument of prodorsum minutely punctate.

Notogaster. Lateral side of notogaster gently swollen. All notogastral setae smooth and thin. Relative lengths and mutual distances of notogastral setae as follows: $h_{2}>h_{1}=e_{2}$ $>p s_{2}>c p=e_{1}=f_{2}>c_{3}=d_{2}=d r_{3}>c_{1}=c_{2}=d_{1}=h_{3}>p s_{1} ;\left(h_{1}-h_{1}\right)>$ $\left(e_{1}-e_{1}\right)>\left(c_{1}-c_{1}\right)>\left(d r_{1}-d_{1}\right) ;\left(h_{1}-h_{1}\right)=2.8 \times\left(c_{1}-c_{1}\right)$. Notogaster provided with parallel ridges running laterally of setae $d_{1}$, $e_{1}$ bifurcating posteriorly, partly extending posterolaterally almost reaching seta $h_{1}$, partly extending medio-posteriorly; transverse ridge present near the posterior end of notogaster just in front of setae $p s_{1}$ where notogaster shows a deep concavity. Integument of notogaster finely punctate. Cerotegument with small widely spaced granules.

Ventral side. Anogenital chaetotaxy 6-0-2-3. Anal plate provided with two setae; $a n_{2}$ minute, hardly visible, situated at a level a little anterior to $a d_{3} ; a n_{1}$ conspicuous, as long as $a d_{3}$, situated at a level posterior to $a d_{3}$. Adanal plate with three moderately long setae. Genital plate with 6 long setae. Relative mutual distances between genital setae as follows: $\left(g_{6}-g_{5}\right) \fallingdotseq\left(g_{5}-g_{4}\right) \fallingdotseq\left(g_{4}-g_{3}\right)>\left(g_{3}-g_{2}\right) \fallingdotseq\left(g_{2}-g_{1}\right)$. Epimera IV fused in the posterior 1/5. Setal formula of epimera: 3-1-33. All epimeral setae very finely barbed and variable in length; $1 b, 3 b, 3 c, 4 a$ and $4 c$ moderately long, $1 c$ and $4 b$ short and the remainder $(1 a, 2 a$ and $3 a)$ minute. Integument of epimera minutely punctate.

Material examined. Holotype and 4 paratypes from St. 1634. Moist moss near stream, under shady trees. Ladybrand, Free State. $29^{\circ} 20^{\prime}$ S, $27^{\circ} 27^{\prime}$ E. 30-IX-1981. C. M. Engelbrecht. The holotype (NMB 1634.1.1) and two paratypes (MNMB 1634.1.2) will be deposited in the
Acarology collection of the National Museum Bloemfontein, South Africa, and two paratypes (NSMT-Ac 11765-11766) in the collection of the National Science Museum, Tokyo.

Remarks. This species is unique in the genus Trimalaconothrus (79 species described to date) in having smooth notogastral setae and barbed epimeral setae.

Etymology. The specific name "rectus" refers to the straight ridges on the notogaster.

\section{Key to species of the family Malaconothridae in South Africa.}

1 (10) Legs monodactyle ................................................ 2

2 (9) Parallel longitudinal and inverted W-shaped ridges present on notogaster ......................................... 3

3 (4) Rostrum square, rostral seta barbed Malaconothrus stigmatus Yamamoto \& Coetzee 2004

4 (3) Rostrum rounded ................................................ 5

5 (6) Translamella present Malaconothrus indifferens Hammer 1966

6 (5) Translamella absent ........................................ 7

7 (8) Four pairs of genital setae present Malaconothrus longidorsus Yamamoto \& Coetzee 2004

8 (7) Five pairs of genital setae present Malaconothrus engelbrechti

Yamamoto \& Coetzee 2004

9 (2) No parallel longitudinal and inverted W-shaped ridges on notogaster

Malaconothrus minimus

Yamamoto \& Coetzee 2004

10 (1) Legs tridactyle ............................................... 11

11 (12) Notogaster shield-shaped, i.e. notogaster tapering posteriorly ....... Trimalaconothrus punctus sp. nov.

12 (11) Notogaster barrel-shaped, i.e. notogaster widening posteriorly 13

13 (18) Lamellar ridge S-shaped ............................... 14

14 (15) Some notogastral setae finely barbed . Trimalaconothrus binodulus sp. nov.

15 (14) All notogastral setae smooth and thin 16

16 (17) Epimeral setae barbed

17 (16) Epimeral setae smooth Trimalaconothrus rectus sp. nov. Trimalaconothrus obesus sp. nov.

18 (13) Lamellar ridge not S-shaped Trimalaconothrus duoaculeus sp. nov.

\section{References}

Berlese, A. 1904. Acari nuovi. Manipulus III. Redia, 2: 10-32.

Berlese, A. 1916. Centuria terza di Acari nuovi. Redia, 12: 289-338. Choi, S. 1986. The oribatid mites (Acari: Cryptostigmata) of Korea (7). Korean J. Syst. Zool., 2(1): 37-42.

Fain, A., Lambrechts, L. \& Wauthy, G. 1990. Observations on the acaroauna of fish aquariums IV: A new Trimalaconothrus, $T$. aquatilis sp. n. (Malaconothridae, Oribatida) from an aquarium containing angel fishes. Entomologia, 60: 103-107. 
Hammer, M. 1958. Investigations on the oribatid fauna of the Andes Mountains. I. The Argentine and Bolivia. Biol. Skr. Dan. vid. Selsk., 10(1): 1-129.

Hammer, M. 1962. Investigations on the oribatid fauna of the Andes Mountains. III. Chile. Biol. Skr. Dan. vid. Selsk., 13(2): 1-96.

Hammer, M. 1966. Investigations on the oribatid fauna of New Zealand. Biol. Skr. Dan. vid. Selsk., 15(2): 1-108.

Stary, J. \& Block, W. 1995. Oribatid mites (Acari: Oribatida) of South Georgia, South Atlantic. Journal of Natural History, 29: 1469 -1481 .

Tarras-Walberg, N. 1985. Trimalaconothrus scimitarum n. sp. (Oribatida: Malaconothridae), an aquatic mite from lake Naivasha. Intl. J. Acarol, 11(1): 17-21.

Yamamoto, Y. 1997. Two new oribatid mites of the family Malaconothridae in Wakayama Prefecture, central Japan. (Acari: Oribatei). Acta Arachnologica, 52(2): 119-124.

Yamamoto, Y. \& Aoki, J. 1971. The fauna of lava caves around Mt.
Fuji-san. VII. Malaconothridae (Acari, Cryptostigmata). Bull. nat. Sci. Mus. Tokyo, 14(4): 579-583.

Yamamoto, Y. \& Aoki, J. 1998. Two new oribatid mites of the genus Trimalaconothrus from Yunnan Province in China. (Acari: Oribatida: Malaconothridae). Edaphologia, 61: 15-21.

Yamamoto, Y. \& Coetzee, A. 2003. The Malaconothrus species from South Africa and Lesotho (Acari: Oribatida: Malaconothridae). Acta Arachnologica, 52(2): 113-126.

Wallwolk, J. 1973. A new species of Trimalaconothrus (Acari: Cryptostigmata), an aquatic oribatid mite from Cameroon. J. Zool., 171: 485-488.

Weigmann, G. 1997. Systematics of central European families and genera of Malaconothroidea (Acari, Oribatida). Abh. Ber. Naturkumdemus. Gorlitz, 69(6): 3-10.

Received March 29, 2004 / Accepted May 20, 2004 